\title{
sciendo CHANGES IN MARINE DIESEL ENGINES OPERATING STRATEGY
}

DOI 10.2478/ntpe-2018-0093

\author{
Dr. Tomasz Lus \\ Polish Naval Academy, Poland
}

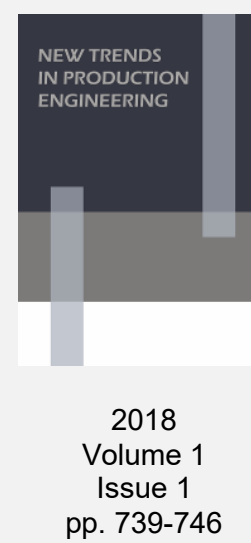

\begin{abstract}
Constant changes in the operating strategy of marine diesel engines are observed. They refer to whole engine and different functional systems of the engine in different range. The paper presents changes in marine diesel engines operating strategy. Gradual transition from simple failure response operating strategy - Corrective Maintenance $(\mathrm{CM})$ to a reliability-oriented strategy - Reliability Centered Maintenance (RCM) has been described together with some remarks about Planed Maintenance (PM) systems and Condition Based Maintenance (CBM) systems with their latest form called CBM+. Some information about changes in diesel engines operating strategy in the Polish Navy (PN) at the turn of the last 35 years is also presented. An attempt to build engine analyzer for high-speed diesel engines at the Polish Naval Academy (PNA) in order to improve submarine diesel engines operating strategy is also described in the paper.
\end{abstract}

Keywords: marine diesel engines, planned maintenance, condition based maintenance, vibration analysis

\section{INTRODUCTION}

Since the fall of the USSR navies in many European countries were enforced to cut numbers of warships and costs of fleet exploitation. In addition to fuel, lubricants and crew salary costs one of the biggest costs is maintenance of the vessel. Depending on the type of ship, a significant share of maintenance costs is the engine maintenance cost. Different navies together with ship classification societies, through many years of experience, have adopted some new maintenance strategies and introduced for example Integrated Condition Monitoring System (ICMS) (McNeill, 2010). This system enables ship-owners to utilize Condition Monitoring (CM) as part of their on-going machinery survey requirements. More recently (Tomlinson, 2015) ships are being recognised as major assets and with that, the application of asset management tools and techniques are being more widely seen within ship management. Condition Monitoring (CM) of any asset could be done as on-line or off-line process. There are condition monitoring systems based on traditionally measured engine's parameters analysis, engine lubricating oil analysis, in-cylinder pressure analysis and others techniques. One of the tools which could be helpful with introducing CM or even ICMS and lowering maintenance costs could be marine diesel engine technical condition monitoring system based on engine vibration signals analysis.

\section{CHANGES TO THE MARINE DIESEL ENGINES OPERATION STRATEGY}

For many years, marine diesel engines were operated according to the number of worked hours - according to Planned Maintenance System (PMS) for instance in United States Navy. After a specified working time, the engine was subject to routine inspection and adjustment, current repairs, medium and major overhauls. The organization of this kind of operation is relatively simple, but it requires a lot of resources in material and time sense. Gradual reduction of operational expenditures at the turn of 20 and 21 centuries in many navies has resulted in a collapse of the PMS, especially at the level of medium or general engine's overhauls made in shipyards. Current engine inspections and repairs carried out in this system have been maintained, but their scope was limited due to the savings on spare parts and other consumables. 
The change in the range of maintenance work on the ship is also affected by changes in service conditions and work at sea. Diesel engines also became more complex and thus their maintenance mostly because of wider electronic equipment installed in many engine's systems. Changes in marine diesel engines subsystems construction, bigger number of electric and electronic components and parts, affected engine's failure rates and failure pattern (distribution of probability of damage).

The time for specialized training of seafarers is reduced, and the professionalism of crew members is lower in some areas.

Table 1 Principle maintenance methods

\begin{tabular}{|c|c|c|c|c|c|c|}
\hline \multicolumn{7}{|c|}{ Maintenance Methods } \\
\hline \multicolumn{2}{|c|}{ Corrective } & \multicolumn{2}{|c|}{ Preventive } & \multirow{2}{*}{\begin{tabular}{l}
\multicolumn{1}{c}{ Predictive } \\
Condition \\
Based \\
Maintenance
\end{tabular}} & \multicolumn{2}{|c|}{ Proactive } \\
\hline $\begin{array}{l}\text { Run to } \\
\text { failure }\end{array}$ & $\begin{array}{l}\text { Run to } \\
\text { destruction }\end{array}$ & $\begin{array}{l}\text { Planned } \\
\text { Maintenance }\end{array}$ & Opportunistic & & $\begin{array}{l}\text { Prognostic } \\
\text { Maintenance }\end{array}$ & $\begin{array}{l}\text { Reliability } \\
\text { Centered } \\
\text { Maintenance }\end{array}$ \\
\hline
\end{tabular}

Source: own elaboration

In this situation, ship-owners technical services have started to move into a new operating strategy to provide higher reliability. Some fleets have changed their assets maintenance strategies in to so-called Reliability Centered Maintenance (RCM) doing this mainly after the aviation industry. RCM strategy incorporates both PMS strategy and CBM strategy. This very expensive strategy was to maintain only in the richest fleets and especially for their most expensive units (for example for nuclear submarines and aircraft carriers). For poorer fleets and less important units a better solution is Condition Based Maintenance (CBM) strategy. In some sources maintenance strategies are divided in to four generations. First generation which refer to Corrective or Reactive Maintenance (or "Run-to-failure maintenance") (Tab. 1 and Fig.1). Second generation which refer to Preventive or Predetermined Maintenance (or "Fix it before it brakes"). Third generation which refer to Predictive Maintenance (or "If it isn't broke, don't fix it"). Fourth generation which refer to Proactive Maintenance (or "Fix it at the right time"). These two last operating system strategies based on sophisticated condition monitoring systems.

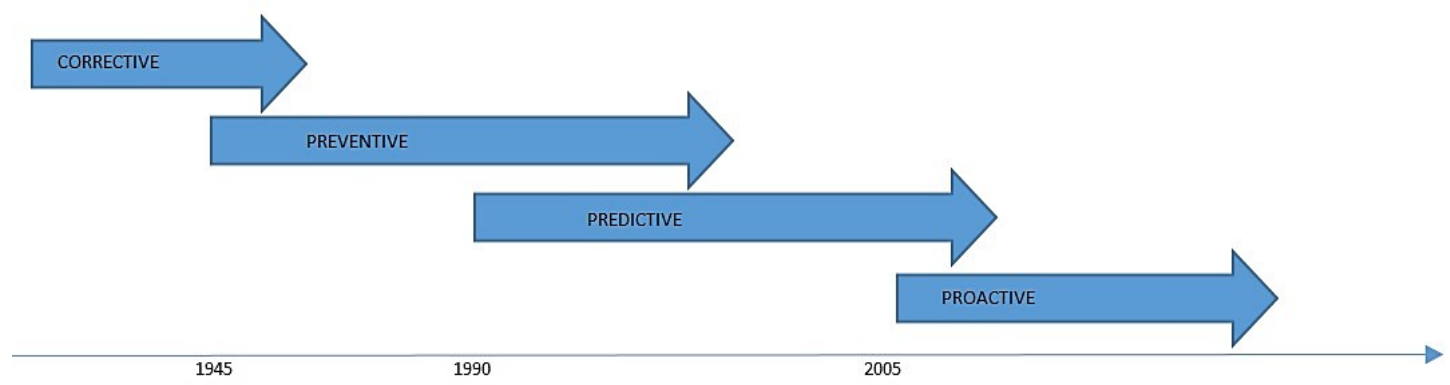

Fig. 1 Evolution of maintenance practices

The first-generation operating system was in force until the end of World War II, and consisted only of repair work after damage occurred. Such maintenance strategy is called Corrective Maintenance (CM) system in which repair work can be done immediately or deferred depending on the reliability structure of the object.

The second generation of reliability-oriented operating systems was developed during and after the Second World War, when more and more complex machines and devices began to be produced. People and industry have become increasingly dependent on machines and their mass production. The increase in this dependence caused the downtime of the damaged equipment to become a very important issue, and caused the idea that equipment damage could and must be prevented, which led to the concept of Preventive Maintenance (PM). As the number of devices increased and the number of failures increased, the costs of preventive maintenance began to grow sharply in relation to overall operating costs. This increase has led to the development of planning and control systems in the area of device operation. This, in turn, allowed the processes of operation of controls to be established and appropriate practices 
established. The dominating nature of the distribution of probability of damage to a secondgeneration system is illustrated by the so-called "bath curve". The collapse of this generation of exploitation strategies in the West occurred in the mid-1970s, but in Poland it was not until the late 1980s.

Table 2 Strengths and weaknesses of different maintenance types

\begin{tabular}{|c|c|}
\hline Maintenance types & Weaknesses and strengths \\
\hline \multirow[t]{2}{*}{$\begin{array}{l}\text { Corrective or Reactive Maintenance } \\
\text { (or "Run-to-failure maintenance") } \\
\text { Breakdown Maintenance }\end{array}$} & $\begin{array}{l}\text { High risk of secondary failure } \\
\text { High production downtime } \\
\text { High costs of spare parts } \\
\text { Overtime labor } \\
\text { Safety hazardous }\end{array}$ \\
\hline & $\begin{array}{l}\text { Machines are not "over maintained" } \\
\text { No condition monitoring related costs }\end{array}$ \\
\hline \multirow{2}{*}{$\begin{array}{l}\text { Preventive or Predetermined Maintenance } \\
\text { (or "Fix it before it brakes") } \\
\text { Planned Maintenance } \\
\text { Scheduled Maintenance } \\
\text { Historical Maintenance } \\
\text { Calendar Based Maintenance }\end{array}$} & $\begin{array}{l}\text { Machines are repaired when there are no faults } \\
\text { Repair often causes more harm than good } \\
\text { There are still "unscheduled" breakdowns }\end{array}$ \\
\hline & $\begin{array}{l}\text { Maintenance is performed in controlled manner } \\
\text { Fever catastrophic failures } \\
\text { Greater control over stored parts and costs } \\
\text { Unexpected machinery failure should be reduced }\end{array}$ \\
\hline \multirow{2}{*}{$\begin{array}{l}\text { Predictive Maintenance } \\
\text { (or "If it isn't broke, don't fix it") } \\
\text { Condition Based Maintenance }\end{array}$} & $\begin{array}{l}\text { High investments costs } \\
\text { Additional skills required }\end{array}$ \\
\hline & $\begin{array}{l}\text { Unexpected breakdown is reduced } \\
\text { Parts are ordered when needed } \\
\text { Maintenance is performed when convenient } \\
\text { Engine live is extended }\end{array}$ \\
\hline \multirow[t]{2}{*}{$\begin{array}{l}\text { Proactive Maintenance } \\
\text { (or "Fix it at the right time") } \\
\text { Prognostic Maintenance } \\
\text { Reliability Centered Maintenance }\end{array}$} & $\begin{array}{l}\text { High investments costs } \\
\text { Additional skills required } \\
\text { Additional time invested upfront } \\
\text { Requires a change in philosophy from management } \\
\text { and down }\end{array}$ \\
\hline & $\begin{array}{l}\text { Equipment life is extended } \\
\text { Reduced downtime } \\
\text { Reduced overall maintenance costs } \\
\text { Equipment reliability improved } \\
\text { Fewer failures, thus fewer secondary failures }\end{array}$ \\
\hline
\end{tabular}

Source: own elaboration on the base of (DoD, 2008)

The third generation of exploitation strategy began in the mid-1970s with the process of industrial change. More and more failures have had a major impact on safety and environmental changes and our dependence on equipment has increased as well as the cost of using and owning them. There was also an increase in service costs in absolute figures as well as in total expenditure. Increased cost effectiveness, increased safety, no environmental hazards, longer equipment life and higher availability and reliability of the plant all of these expectations were included in the new approach to the assets operation. Recent scientific research is changing many of our basic beliefs about the duration and frequency of device failures. In particular, it becomes clear that there is less and less dependency between the time of operation of the device and the probability of its occurrence. It is true especially when asset consist not only from mechanical parts and subsystems but also electric and electronic parts. Such a situation has led to the search for other also cheaper operating strategies such as Condition Based Maintenance (CBM) system which are based on asset Condition Monitoring (CM) equipment.

Last two decades bring a lot of new technology in sensors area, signals and information transmit and computation, artificial intelligence and so on, which create environment to implement proactive maintenance strategy.

At the beginning of the $21^{\text {st }}$ century, the Department of Defense (DoD) of the United States of America and the US Navy deployed the system called Condition Based Maintenance Plus $(\mathrm{CBM}+)$ which "is the application and integration of appropriate processes, technologies, and knowledge-based capabilities to improve the reliability and maintenance effectiveness of DoD systems and components. At its core, $\mathrm{CBM}+$ is maintenance performed based on evidence of 
need provided by Reliability Centered Maintenance (RCM) analysis and other enabling processes and technologies. CBM+ uses a systems engineering approach to collect data, enable analysis, and support the decision-making processes for system acquisition, sustainment, and operations." (DoD, 2008). The full implementation of the CBM + operation strategy requires, according to DoD, the creation of a suitable infrastructure in the eight areas shown in Figure 2.

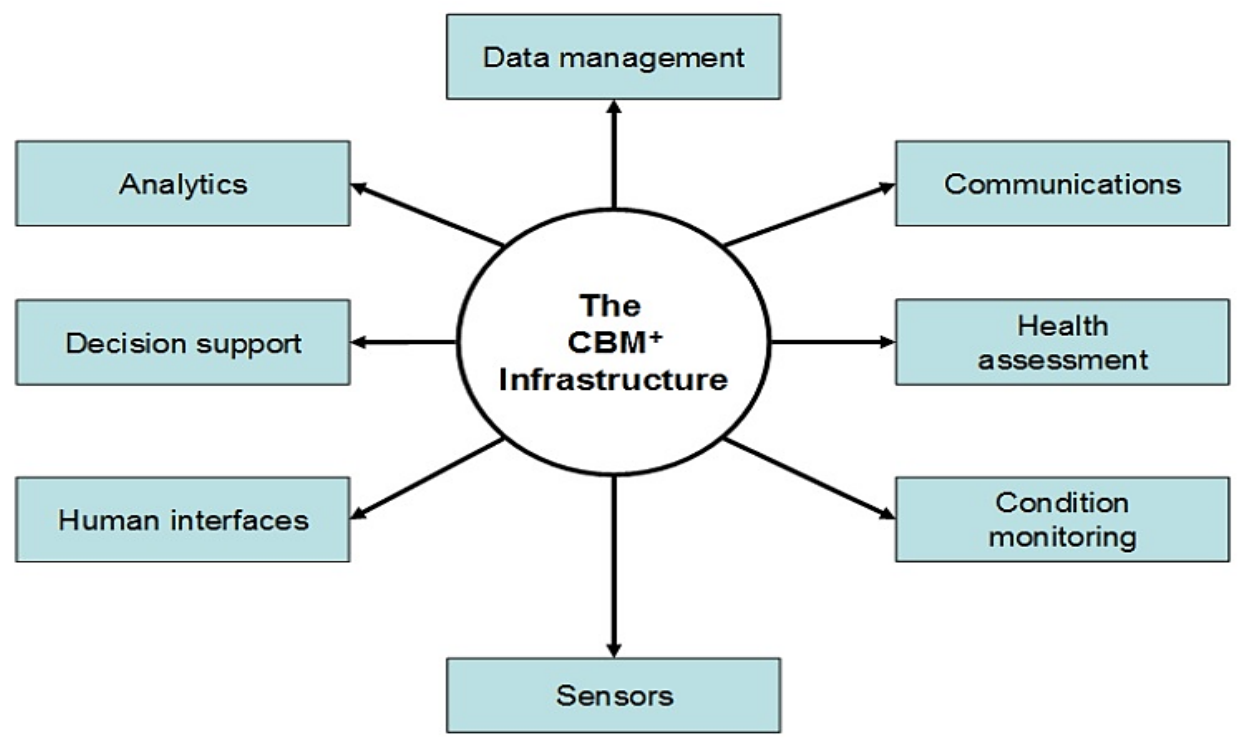

Fig. 2 Infrastructure areas of Condition Based Maintenance + strategy according to US DoD Source: (DoD, 2008)

Only large fleets such as the US Navy, the Royal Navy or similar can afford to build this type of system, the operation strategy. This does not mean that smaller fleets do not try to create similar solutions.

To provide independent confirmation and verification of engine condition some authors (Haller and Kelleher, 2000) suggest implement so called Integrated Maintenance system, which combines a number of diagnostic tools such as:

- Combustion signature analysis and cylinder power balancing;

- Vibration and ultrasonic signature analyses of cylinder components, bearings, valve train, turbochargers, and engine auxiliaries;

- Chemistry analysis of jacket water, lube oil and fuel oil;

- Non-intrusive internal visual inspections;

- Exhaust gas analysis;

- Thermography;

- Trend line analysis of engine operating parameters (temperatures, pressures, levels, etc.).

The purpose of such approach is to maximize profit for ship operators via: reduced fuel consumption, reduced maintenance, increased reliability, increased availability and maximized horsepower.

Manufacturers of marine diesel engines in agreement with manufacturers of ship auxiliary electronic equipment and engine control equipment gradually create conditions for building similar to CBM + systems, albeit limited in size and functionality.

For example in the Caterpillar company (Shafiepour and Krooner, 2010) diesel engines faulty fuel injectors could be identified to save fuel using onboard sensors and data analytics as part of the Caterpillar Marine Asset Intelligence (MAI) technology platform. The analytics are able to identify when the fuel injectors are likely fouled even before their scheduled replacement by analyzing the exhaust temperatures, engine speed, and fuel consumption. The analytics identified specific fuel injectors that were likely fouled all of which would not be able to be identified by the onboard crew because the engine appeared to be operating normally. According to authors, fuel injectors malfunction were costing an extra $\$ 175$ per day in excess 
fuel consumption (equivalent to $\$ 52,500$ per year). In this case, the fuel injector replacement paid for itself in approximately three days as well as reduced wear on the engine and avoided a potentially catastrophic engine casualty.

Another example is the Wärtsilä company, the one of the biggest marine diesel engine manufacturers, with its technical management concepts (Klockars, Eykerman and Mayr, 2010) cuts costs for ship owners by online monitoring and Dynamic Maintenance Planning (DMP). To prepare Dynamic Maintenance Plan marine diesel engines have to be equipped with Condition Monitoring (CM) system which is standard for Wärtsilä latest design engines.

To increase reliability, optimize performance and reduce maintenance costs in diesel engines operation the WINDROCK from Knoxvill, TN, USA (part of the Dover Energy Automation/Dover Corporation company) offers diesel engines analysers. According to WINDROCK (windrock.com, 2016) traditional diesel analysis relies solely on measurements of cylinder pressure versus crank angle ("indicator cards"). While useful for measuring engine performance, this method fails to identify the mechanical condition of components. Vibration monitoring and analysis is a proven technology used to identify component degradation and reduce failures of rotating equipment. However, this spectrum or frequency based approach is impractical and cannot be effectively used for diesel engines and other reciprocating machinery. For over 25 years, WINDROCK successfully used crankshaft referenced vibration and ultrasonic vibration measurements to assess the mechanical health of reciprocating machines. Crankshaft reference data is time based, not spectrum based, and allows simple visualization and analysis of internal components (Fig. 3).

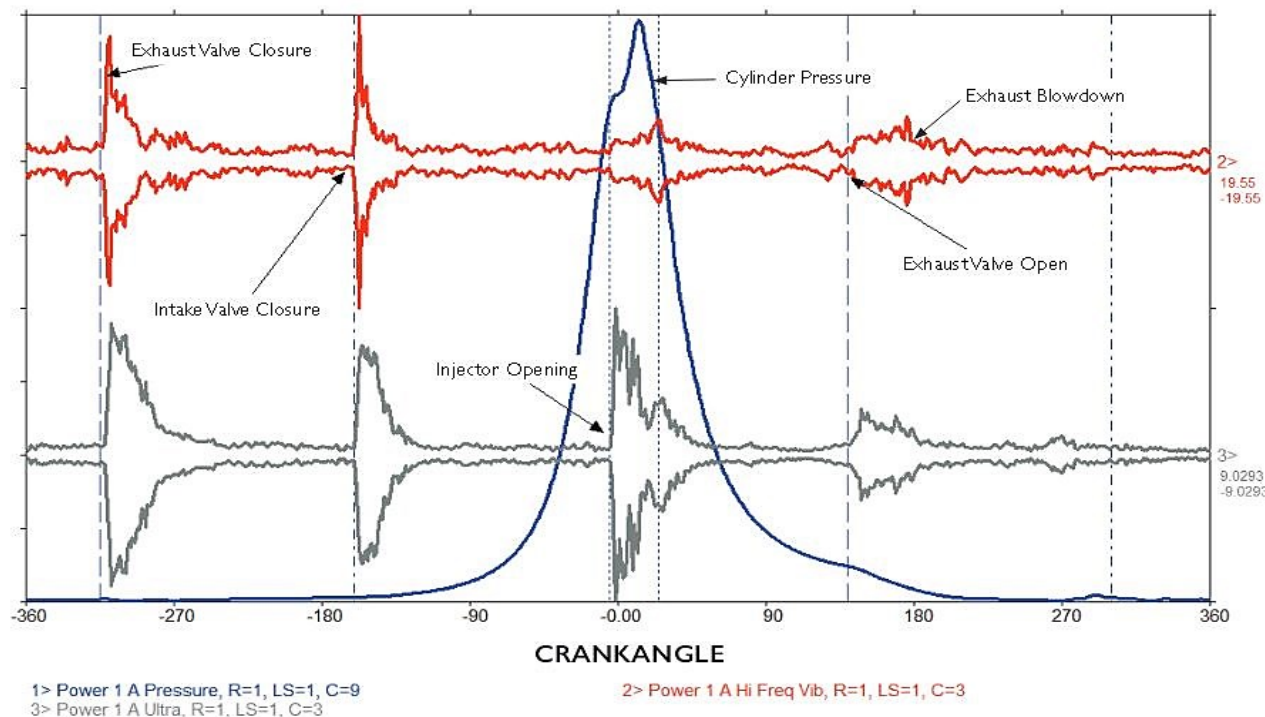

Fig. 3 A time based reference that allows for simple visualization and analysis of internal components

Synchronizing the position of the crankshaft and resultant piston position throughout the stroke and then plotting a once-per-degree resolution allows all internal mechanical events to be visualized. It also provides a clean signature of valve events, injector events and abnormalities such as liner wear and bearing degradation. Advanced WINDROCK MD analysis software and its automated diagnostics features make analysis and reporting simple. Combining crank-anglebased vibration and ultrasonic technology with traditional indicator card readings gives a full, easy-to-interpret assessment of the condition and performance of all types of diesel engines.

\section{CHANGES TO THE MARINE DIESEL ENGINES OPERATION STRATEGY IN THE POLISH NAVY}

In spite of a significant reduction in the number of vessels, the Polish Navy (PN) has gradually been equipped with new types of marine piston engines. The new engines are modern with modern control and safety systems equipped with sensor-filled devices. Thanks to this, these 
engines are easy to adapt to the implementation of Condition Monitoring (CM) systems and new operating strategies. However, a significant part of the PN's prime movers are older diesel engine types with conventional control and safety systems. Engines built several decades ago are not susceptible to diagnostics and, unfortunately, cannot be operated in the CBM system without having their own built-in monitoring and diagnostic systems. Trying to adopt similar maintenance systems to the older generation of marine diesel engines the appropriate condition monitoring tools have to be prepared.

The Polish Naval Academy (PNA) in Gdynia conducts research for the construction and development of such systems, and maintains diagnostics teams for marine diesel engines in the Technical Institute of Ships Construction and Maintenance.

Almost all prime movers in PN are systematically tested with advanced diagnostic systems worked out in PNA in order to subject them to a modern operating system. Assessment of the technical condition of internal combustion engines on-board the ship is a very complex process. The PNA's advanced diagnostic system for diesel engines which based on in-cylinder pressure analysis, visual endoscopic analysis and engine vibration signal analysis is used together with adopted in whole PN lubricating oil analysis system. Despite this, when planning resources for the operation of diesel engines, it should not be forgotten that even with the most advanced monitoring and diagnostics systems it is not always possible to avoid engine damage.

Replacing the PM strategy in marine diesel engines with the new, more cost-effective CBM strategy in the PN is slowly becoming a reality. However, there are still many engines whose operation must follow the old system, according to the old strategy. In those cases where it is possible to use a new diagnostic method, which does not require too much work, and their price and information are becoming more and more attractive when it comes to CBM operation strategies. The acquisition of new vessels for PN should be linked to the implementation of modern propulsion systems and diesel engines that can be easily incorporated into the maintenance system according to technical condition - CBM system.

PNA has been researching the construction and development of marine diesel engine condition monitoring systems (Lus and Łutowicz, 2010) which are based on:

- in-cylinder pressure analysis;

- engine vibration analysis;

- engine internal parts visual endoscopic analysis;

- lubricating oil analysis.

Example of such a system worked out in the PNA, based on engine vibration and in-cylinder pressure analysis, will be presented in the next chapter.

\section{EXAMPLE OF ENGINE CONDITION MONITORING SYSTEM ELABORATED IN THE PNA}

Internal cylinder pressure curve analysis is used in the assessment of the technical condition of slow-speed and medium-speed marine diesel engines. Cylinder pressure transducers are mounted on the cylinder indicator valves. In high-speed diesel engines that are not normally fitted with indicator valves by the factory, other diagnostic methods such as vibro-acoustic may be used to evaluate the combustion process, to assess the technical condition and the tightness of the cylinders, and to adjust the fuel equipment and valve gear mechanism. In the case of piston internal combustion engines, typical methods of vibration signal analysis in the time or frequency domain usually provide limited information. In addition, methods used in marine diesel engine diagnostics based on vibration analysis are susceptible to interferences resulting from changes in rotational speed and engine load. The method presented in this article could be described as a vibration signal pattern visual analysis in the angle of the crankshaft rotation domain of the envelope of vibration acceleration signal generated by the functional systems of the operating engine. This method was elaborated at the PNA for slow- and medium-speed marine diesel engines and is still developed for other types of marine diesel engines including high-speed diesel engines used on-board submarines. Complete measuring system used in this method consists of: laptop-analyzer with special software (Figure 3), 6 calibrated vibration sensors with cables for 6 engine's cylinder heads in one block, 1 cylinder pressure sensor to fix on the cylinder safety drainage valve. 


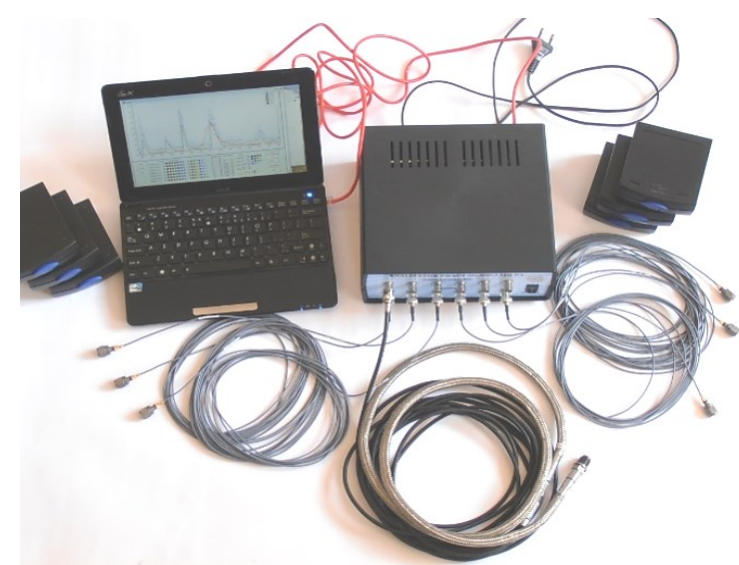

Fig. 3 Submarine internal combustion diesel engine condition monitoring system built in PNA

In this method the vibration signal is analyzed as an event in the time/crank-angle axis of the engine crankshaft rotation. With a sufficiently high vibration signal sampling rate and a stable crankshaft rotation time/angle axis, having a suitable reference signal, it is possible to easily determine the characteristic points of the engine vibration acceleration envelope (Fig. 4) generated by the individual cylinder fuel injectors and valve gear subsystems.

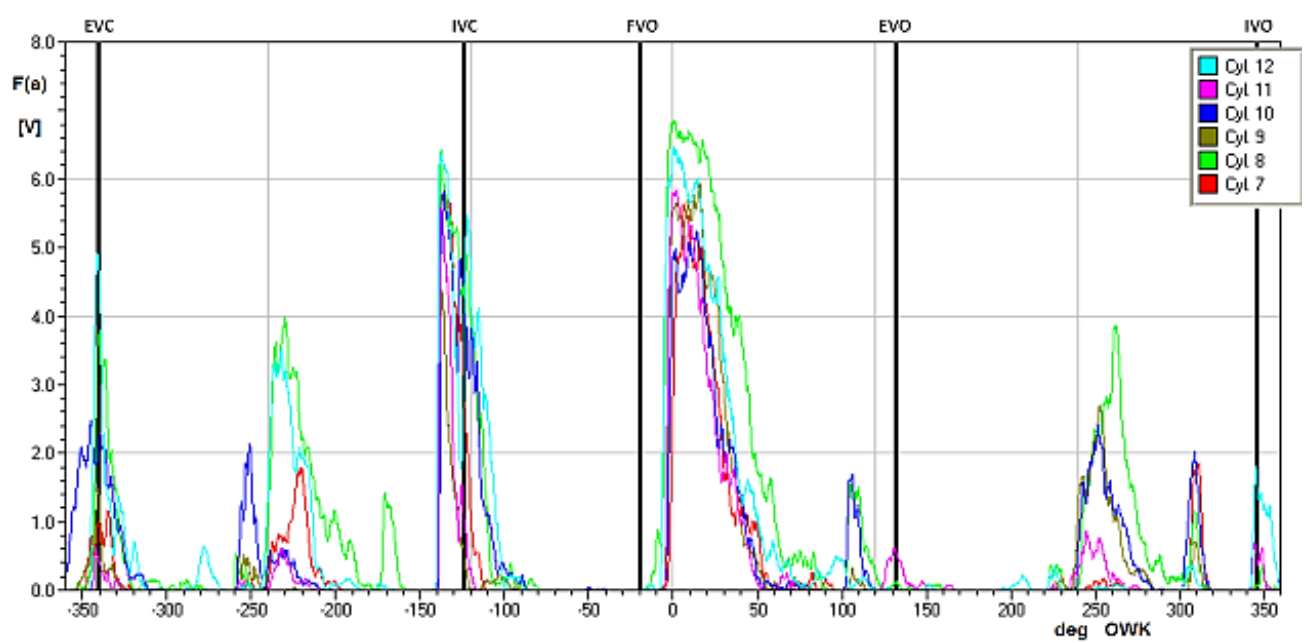

Fig. 4 Signals of vibration acceleration envelopes from six cylinder heads moved to the TDC of the first cylinder in the block - MB820 type engine

EVC - exhaust valve closing, IVC - intake valve closing, FVO - fuel valve opens, EVO - exhaust valve opens, IVO - intake valve opens

By using the analyzer with the so called "zoom" function, each part of the vibration acceleration envelope waveform can be enlarged what make it easier to read out values of angles of the engine timing phases. Using the cursor, analyzer operator can determine the angles of the opening and closing of the fuel injectors (Fig. 5), and the angles of closing and opening of the intake and exhaust valves (Fig. 6).

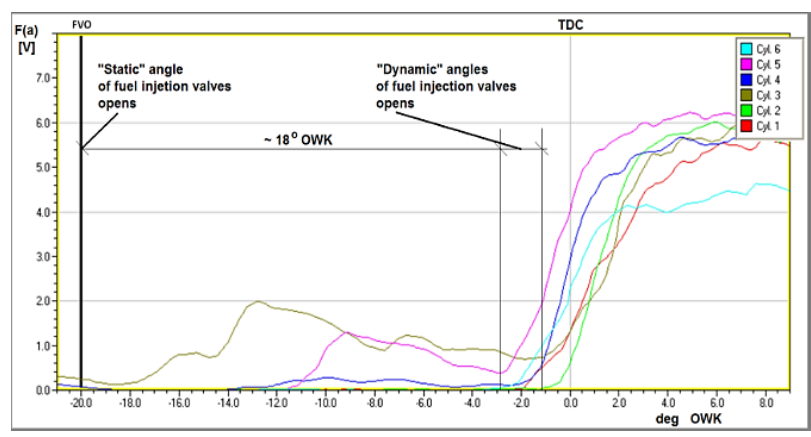

Fig. 5 Static and dynamic angles of the opening of the fuel injectors 


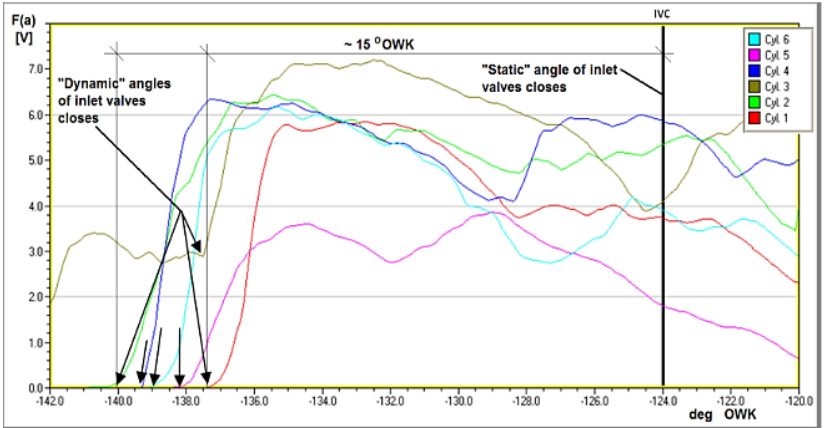

Fig. 6 Static and dynamic angles of closing of the inlet valves

\section{CONCLUSIONS}

The operating costs of ships are high. It is estimated that on average they are four times higher than the costs of construction or purchase of a ship. Significant contributions to the overall maintenance cost of the ship are the operating costs of marine diesel engines. In order to reduce these costs, engines maintenance strategies are constantly improved. Maintenance strategies could be divided in to four generations: first generation - Corrective Maintenance; second generation - Preventive Maintenance; third generation - Predictive Maintenance; and forth generation - Proactive Maintenance. In the future, most of the new engines will be maintained on the base of their actual technical condition. Solutions from engine condition monitoring systems developed for older engine types, to some extent, could be used in a new engine's maintenance systems.

\section{REFERENCES}

Haller, C.L., Kelleher, E. (2000). Practical Integrated Maintenance and Diagnostics for Medium and Slow Speed Diesel Engines. SNAME ASNE SMPE, Alexandria, VA, USA.

Klockars, T., Eykerman, A., Mayr, I. (2010). Making the most of perfect maintenance timing, indetail, Wärtsilä Technical Journal, 01.2010, pp. 57-60, Finland.

Lus, T., Łutowicz, M. (2010). Preliminary tests of envelope vibration diagnostic method on marine high-speed diesel engine. Research papers of IAg Eng LUA \& LU of Ag, vol 41, no 1-2, pp. 86-97, Lituania.

McNeill, E. (2010). Condition monitoring maintenance. Goorangai, Occasional papers of the Royal Australian Naval reserve professional studies program, Volume 4, Number 3.

Schantz, J. (2012). Condition based maintenance - submarine A26. Division of Industrial Electrical Engineering and Automation, Faculty of Engineering, Lund University, Sveden.

Shafiepour, R., Krooner, K. (2010). Smart condition based maintenance system (SMART CBM). Caterpillar Marine Asset Intelligence, USA.

Tomlinson, N.A.,(2015). What is the ideal maintenance strategy? A look at both mod and commercial shipping best practice. BMT Defence Service, UK.

DoD.mil, (2008). Condition based maintenance plus, Department of Defense Guidebook.[online] Available at: https://www.dau.mil/guidebooks/Shared\%20Documents/Condition\%20Based\%20

Maintenance\%20Plus\%20(CBM+)\%20Guidebook.pdf

Windrock.com, (2016). Diesel Engine Diagnostic Solutions. Maximize efficiency and avoid catastrophic failures. Knoxville, TN, USA. [online] Availableat: http://www.amesolutions.com/wp3/

wp-content/uploads/1-Windrock-Diesel-Engine-Diagnostic-Solutions-Brochure.pdf 